\title{
Diurnal Cycle of Rainfall and Convective Properties over West and Central Africa
}

\author{
Richard Ayodeji Balogun, Elijah Adesanya Adefisan, Zechariah Debo Adeyewa, \\ Emmanuel Chilekwu Okogbue, Ademola Akinbobola
}

Federal University of Technology Akure, Akure, Nigeria

Email: rabalogun@futa.edu.ng

How to cite this paper: Balogun, R.A., Adefisan, E.A., Adeyewa, Z.D., Okogbue, E.C. and Akinbobola, A. (2022) Diurnal Cycle of Rainfall and Convective Properties over West and Central Africa. Atmospheric and Climate Sciences, 12, 74-85. https://doi.org/10.4236/acs.2022.121006

Received: August 30, 2021

Accepted: January 1, 2022

Published: January 4, 2022

Copyright $\odot 2022$ by author(s) and Scientific Research Publishing Inc. This work is licensed under the Creative Commons Attribution International License (CC BY 4.0).

http://creativecommons.org/licenses/by/4.0/

(c) (i) Open Access

\begin{abstract}
The need to investigate diurnal weather cycles in West Africa originates from the fact that complex interactions often result between mesoscale and synoptic weather processes. This study investigates diurnal cycles of rainfall and convective properties using six (6) hour interval data from the ERA-Interim and derived products from the Tropical Rainfall Measurement Mission (TRMM). Results showed that the land-ocean warming contrast is more strongly sensitive to the seasonal cycle, being very weak during March-May (MAM) but clearly spelled out during June-September (JJAS). Dipoles of wind convergence/divergence and wet/dry precipitation, between CASS and Nigeria Savannah zones, were identified in the morning and evening hours of MAM, whereas distinct night and day anomalies, same location in CASS, were found to be consistent during the JJAS season. The locations of flash count and system sizes agree with the climatology of convective properties, that morning and day-time hours are dominated by stratiform precipitation and small system sizes. Most results clearly showed that the eastern locations of Sudano and Sahel are consistently dry because rainfall and precipitation features are predominantly few. Very unique results about the dipole of wind and precipitation between two zones and the unusual dry zones of Sudan and Sahel have been found. Results presented had shown the importance of diurnal variation in understanding precipitation, flash count, system sizes patterns at diurnal scales, and understanding land-ocean contrast, precipitation and wind field anomaly at diurnal scales.
\end{abstract}

\section{Keywords}

Convective, Diurnal Cycle, Flashcount, System Sizes

\section{Introduction}

In tropical West Africa (near the Guinea Coast) deep convection in the boreal summer has been found to develop in the late afternoon and reaches a maximum 
in the evening. In this part of West Africa, the diurnal cycle of convection has been shown to correspond with boundary layer destabilization caused by daytime insolation and surface energy fluxes [1]. [2] observed a link between daily averages of rainfall during summer and the West African Monsoon, and that intra-seasonal precipitation usually occurs during the transitional periods of the Monsoon (see also [3]), and the dry seasons occasionally produce unseasonal precipitation. In the semi-arid regions of the Sahel however, convection has been found to initiate in the evening, with peak precipitation rates occurring in the early morning ([4] [5]). This is similar to results by [6] that westward propagating storms in the Equatorial regions of the Rift Valley, Lake Victoria and part of the Congo Forest tend high precipitation rates. Their work also showed that precipitating systems usually commence during the afternoon to early morning hours [6] particularly in the Eastern Lake Victoria and Western Rift Valley. The diurnal cycle of convection in the Sahel has in large part been explained by the westward propagation of MCSs throughout the region. In West Africa, MCSs are often triggered by elevated daytime heating and orography [7]. These storms typically propagate westward away from their source regions, such that the timing of peak precipitation occurs later and later as the MCS moves farther and farther away from its source region [8]. The seven distinct zones used in this work (Figure 1) and classified as rainforest (west-coast, dry, Nigeria-Cameroon), savannah (Nigeria, Central Africa and South Sudan (CASS)), Sudano-Sahel, and Sahel, were clearly spelled out by their rainfall patterns. In a study by [3], West Africa was divided into seven climate zones based on vegetation and rainfall characteristics. A detailed description of each of the zones used in this study can be found in the aforementioned journal.

This paper is motivated by the fact that diurnal cycle of convective parameters, such as flash counts and system sizes, over West Africa covering the Sahel region have diurnal variability which is important for sub-seasonal to seasonal (S2S) forecasting. The authors aim to investigate diurnal pattern/distribution and characteristics of convective properties.

\section{Data and Methodology}

The Tropical Rainfall Measuring Mission (TRMM, [9]) is a joint mission between NASA and the National Space Development Agency (NASDA) of Japan designed to monitor and study tropical and global rainfall. Onboard TRMM instruments include: Precipitation Radar (PR), TRMM Microwave Imager (TMI), Visible Infrared Radiometers (VIRs), Cloud and Earth Radiant Energy Sensor (CERES) and Lightning Imaging Sensor (LIS). The TRMM instruments provide invaluable measurements of atmospheric precipitation. This work utilized 16 years (1998 to 2013) TRMM data for analysis. This research work used high resolution $\left(0.1^{\circ} \times\right.$ $0.1^{\circ}$ ) TRMM 2A25 radar-derived rainfall product, alongside the European Centre for Medium-range Weather Forecasts (ECMWF) interim reanalysis (ERA-Interim: [10] [11]) zonal and meridional winds (fixed $0.75^{\circ}$ gridded) 10 meter $\mathrm{U}$ and $\mathrm{V}$ wind fields, to investigate diurnal distribution of wind and precipitation. The diurnal anomalies were also computed to investigate the dry and wet zones in West 
Africa, and to identify divergent and convergent zones, and their relationship with the dry and wet areas in West Africa. The convective properties of flash count and system sizes were also investigated at diurnal scales.

\section{Results and Discussion}

\subsection{Distribution of Wind and Rainfall}

Figures 2(a)-(e) and Figures 3(a)-(e) are the spatial distribution of winds and

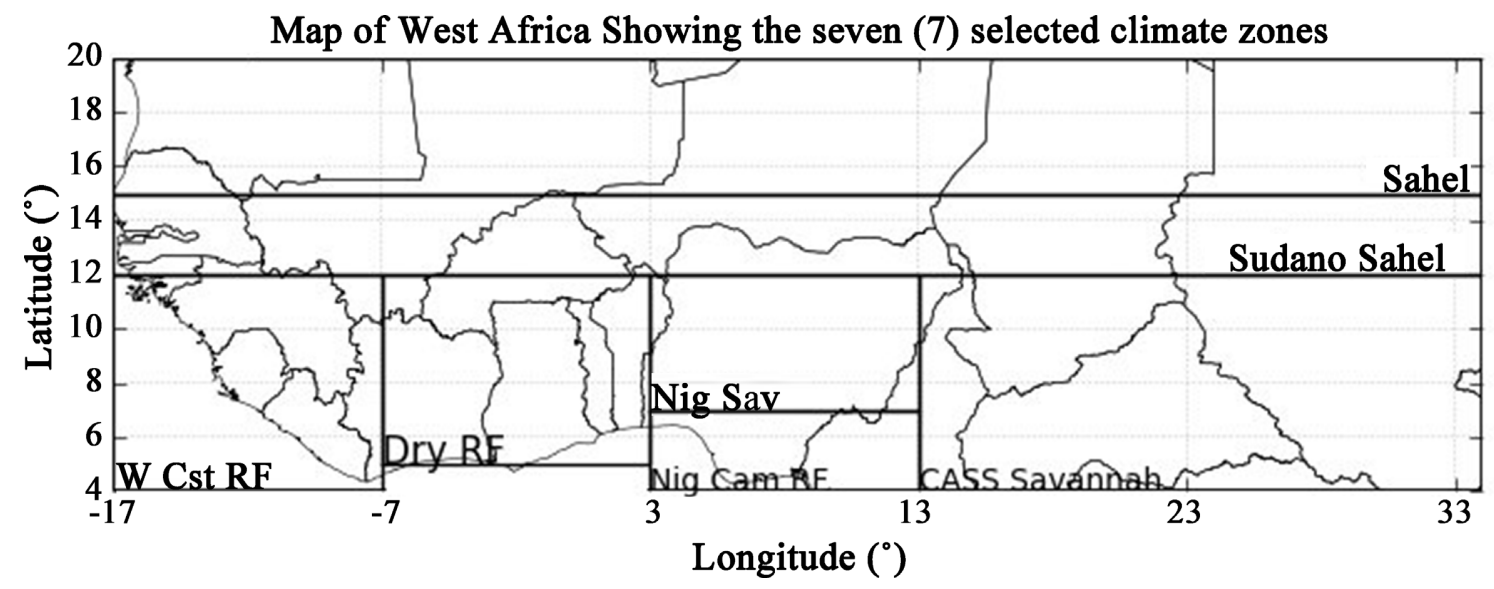

Figure 1. Study area showing the seven (7) selected climate zones.
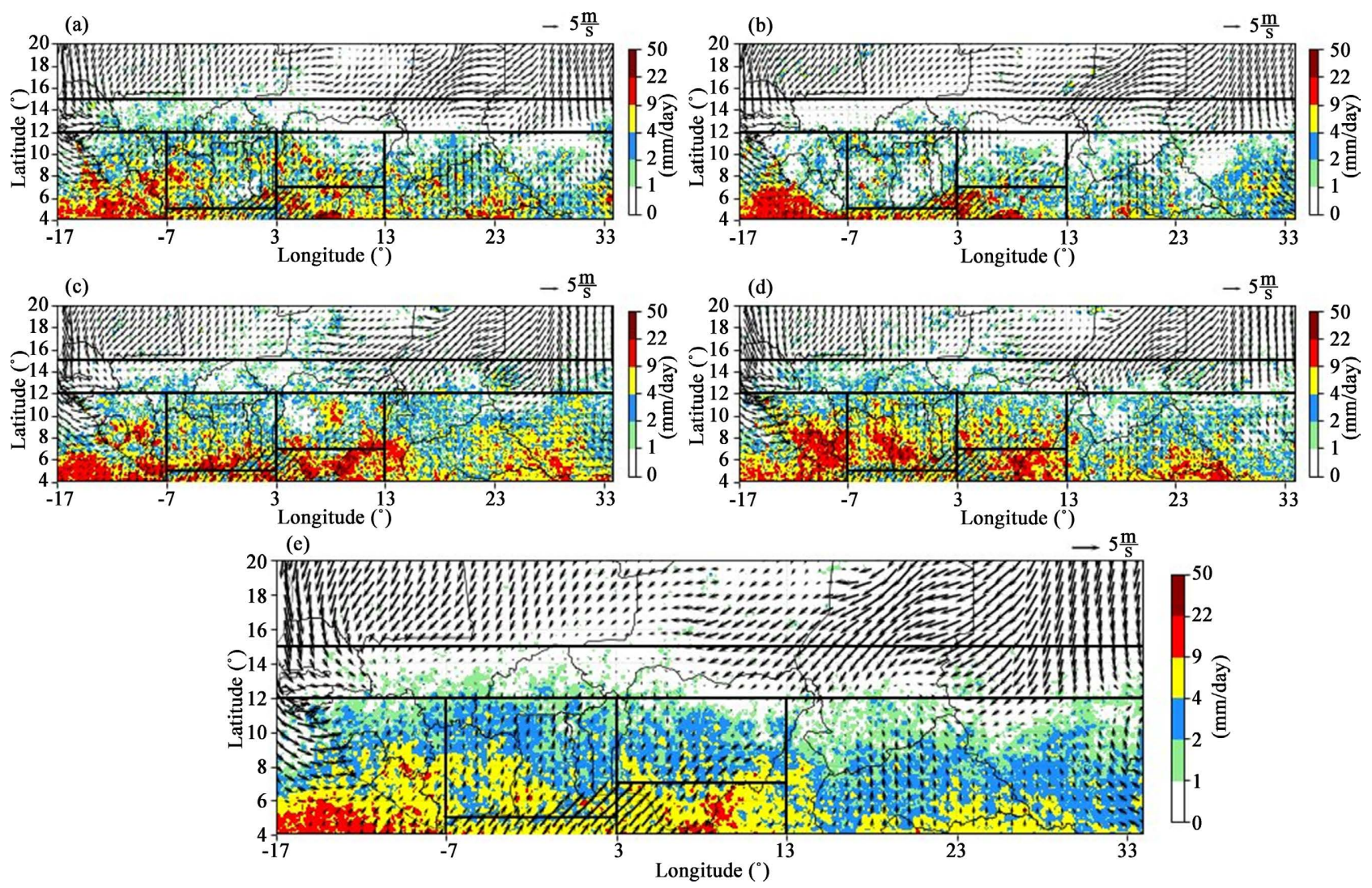

Figure 2. Mean (1998-2014) diurnal 10-meter wind from ERA-Interim and TRMM radar-derived precipitation during MAM for (a) (00 - $06 \mathrm{Z})$, (b) (06 - 12 Z), (c) (12 - 18 Z), (d) (18 - $23 \mathrm{Z})$, and (e) (00 - $23 \mathrm{Z})$. 

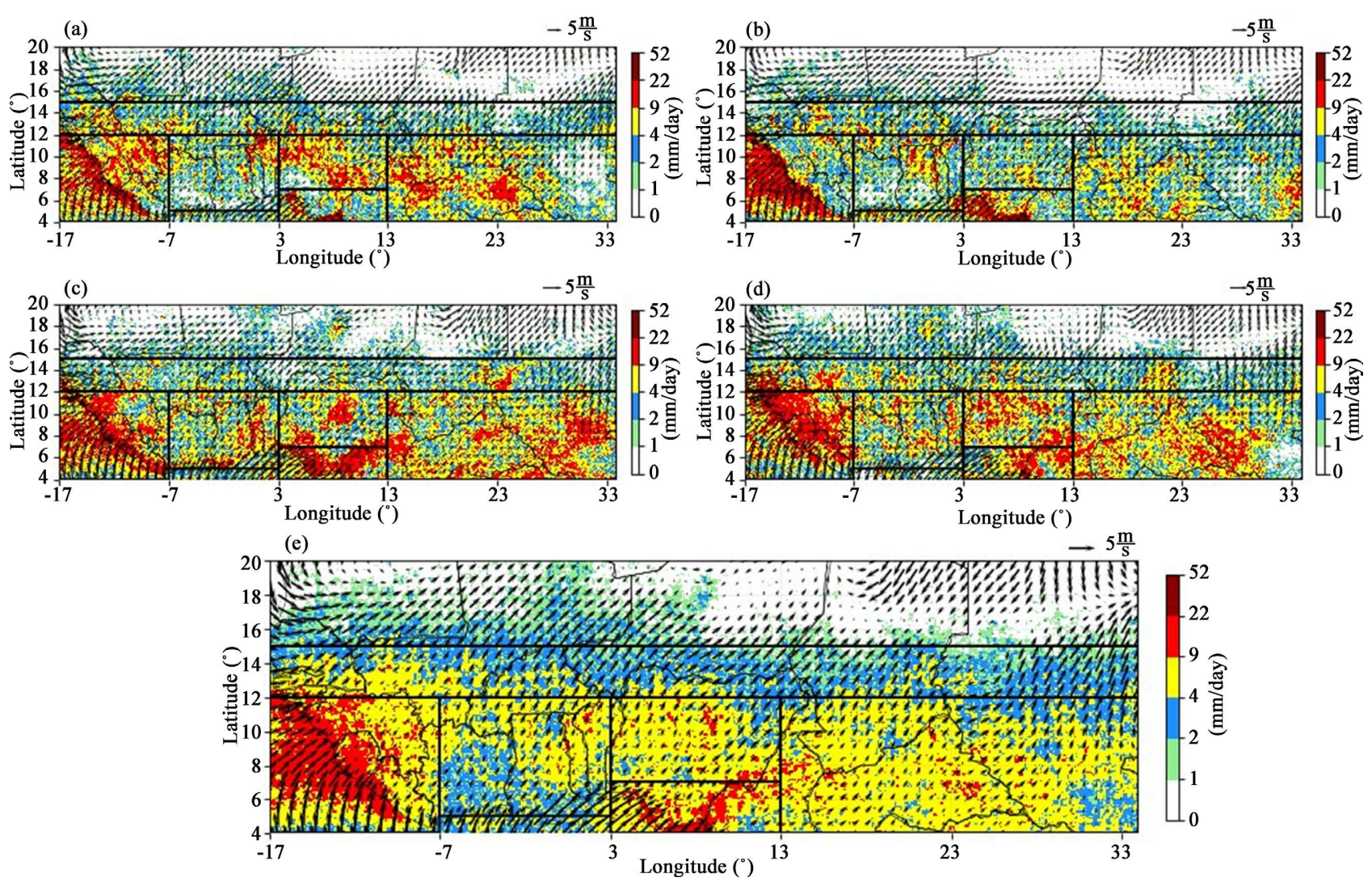

Figure 3. Mean (1998-2014) diurnal 10-meter wind from ERA-Interim and TRMM radar-derived precipitation during JJAS for (a) (00 - $06 \mathrm{Z})$, (b) (06 -12 Z), (c) (12 - 18 Z), (d) (18 - 23 Z), and (e) (00 - 23 Z).

rainfall at different diurnals during the MAM and JJAS seasons respectively. Consistent with result presented, [12] and [13] had shown that rainfall in the Sudano and Sahel are generally shallow with marginal (insignificant) increase during MAM but a significant increase during JJAS. This may be due to the continued dominance or strong presence of the dry-ladden north easterly winds in MAM and strong presence of the moisture-ladden south westerlies during JJAS in Sudano and Sahel zones. The Nigeria-Cameroon and west-coast rainforest distinctly indicated higher rain rate ( $\mathrm{mm} /$ day) in both MAM and JJAS when compared with the other zones that are south of 10 degrees north. This is consistent with results from [14] and [15]. [16] used data for Ghana to show that the dry rainforest zone has two-peak rainfall (similar to rainforest classification) and annual rainfall between 850 and $1350 \mathrm{~mm}$, with 6 - 10 dry months (<100 mm rain) similar to savannah annual rainfall. Another observation in Figures 2(a)-(e) and Figures $3(a)-(e)$ is the presence of a rainfall land-ocean contrast. A mechanism proposed by [17] on enhanced warming of land domains relative to ocean explains, for both MAM (Figures 2(a)-(e)) and JJAS (Figures 3(a)-(e)), why the ocean had more rainfall than land during the morning hours whereas during the evening hours the land experience more rainfall than the ocean. The land-ocean monsoonal rainfall contrast is highly/strongly sensitive to diurnal cycle both during MAM and JJAS seasons whereas the 2-meter surface temperature in JJAS (not shown) showed that 
the land-ocean warming contrast could be partly sensitive to seasonal cycle, been very weak during MAM (not shown) but clearly spelt out during JJAS.

\subsection{Distribution of Wind and Rainfall Anomaly}

The diurnal wind and precipitation anomaly were investigated, to provide more results, especially to establish dry and wet locations and locations of wind convergence and divergence. In Figures 4(a)-(d), a dipole of wind convergence/ divergence and wet/dry precipitation were identified in morning (6 Z, Figure $4(\mathrm{~b}))$ and evening (18 Z, Figure 4(d)) diurnals of MAM. A dry and wind divergence zone is in the Nigeria Savannah while simultaneously a wet and wind convergence zone is in Central Africa and South Sudan (CASS) Savannah during the morning (6 Z, Figure 4(b)) diurnal. On the other hand, during the evening diurnal, a wet and wind convergence zone is in the Nigeria Savannah while simultaneously a dry and wind divergence zone is in Central Africa and South Sudan (CASS) Savannah. [14] showed a dipole between southern and northern zones of West Africa, but the dipole observed here is between Central Africa and Nigeria Savannah. In Figures 5(a)-(d), a distinct night (0 Z, Figure 5(a)) and day (12 Z, Figure 5(c)) diurnal anomaly of wind and precipitation were observed, in Central Africa and South Sudan (CASS) Savannah zone, during the JJAS season. That is, the night (0 Z) diurnal is consistently dry in a location in CASS Savannah while the same location is found to be consistently wet during the day $(12 \mathrm{Z})$ diurnal. Another close location, in the CASS Savannah zone, exhibits this distinct diurnal anomaly during the morning (6 Z, Figure 5(b)) and evening (18 Z, Figure 5(d)) diurnals. It is found to be consistently wet during the morning diurnal but consistently dry during the evening diurnal. These locations are zones where moisture was transported, discussed in an earlier section on monsoonal moisture transport.
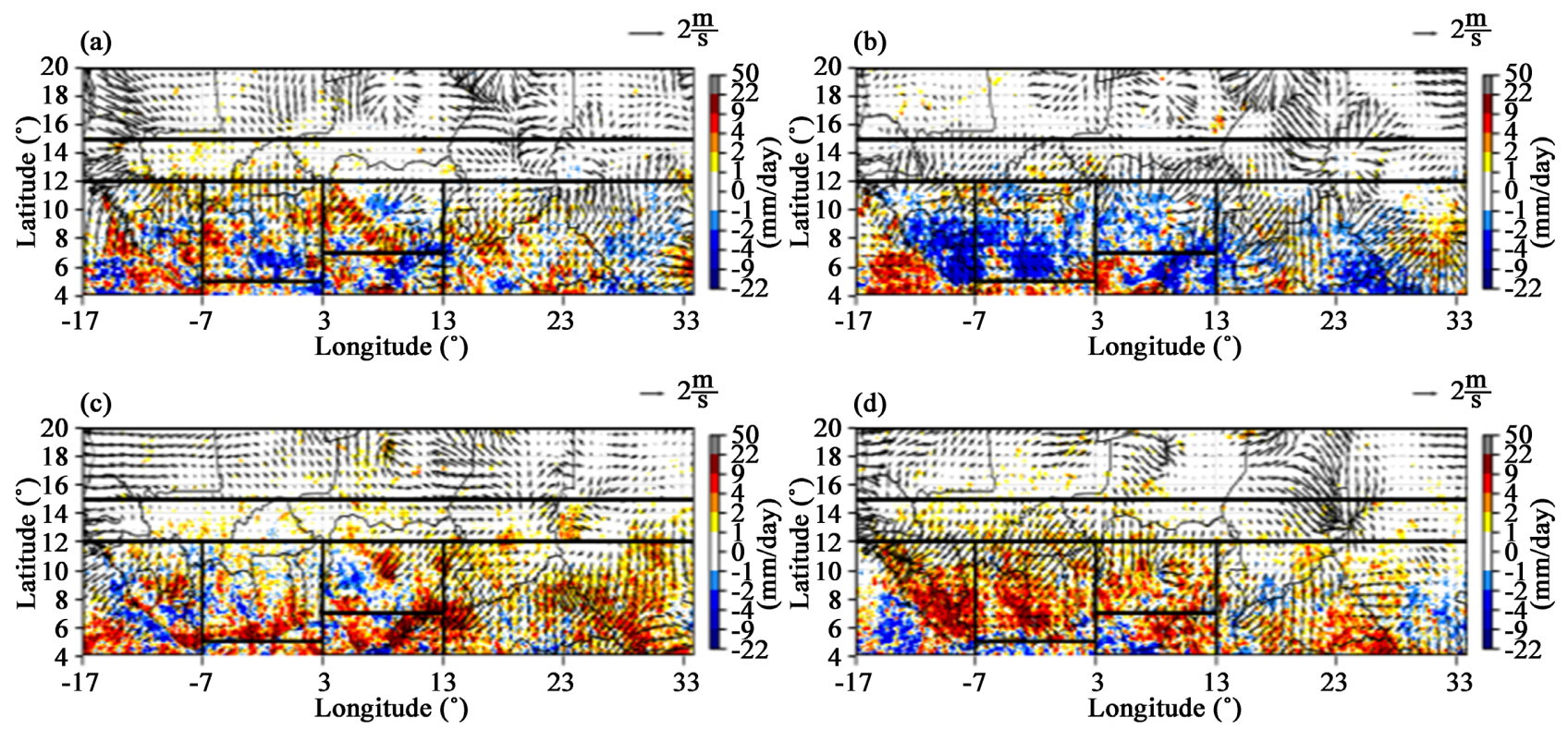

(d)

$-2 \frac{\mathrm{m}}{\mathrm{s}}$

Figure 4. Mean (1998-2014) diurnal anomalies of 10-meter wind from ERA-Interim and TRMM radar-derived precipitation during MAM for (a) (00 - 06 Z) (b) (06 - 12 Z) (c) (12 - 18 Z) (d) (18 - 23 Z). 

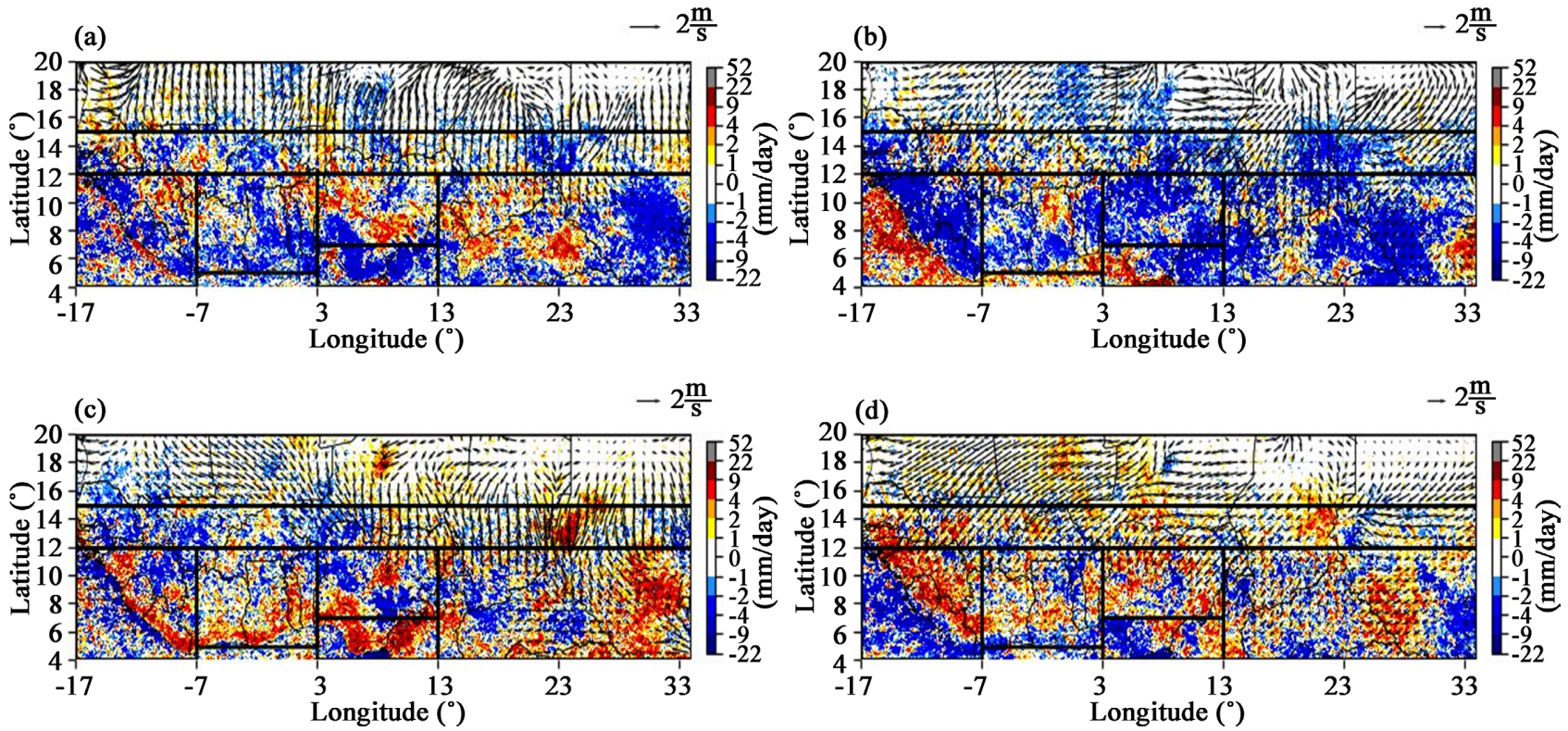

Figure 5. Mean (1998-2014) diurnal anomalies of 10-meter wind from ERA-Interim and TRMM radar-derived precipitation during JJAS for (a) (00 - $06 \mathrm{Z})$, (b) (06 - 12 Z), (c) (12 - 18 Z), (d) (18 - $23 \mathrm{Z})$.

\subsection{Diurnal Variation of Convective Properties}

In discussing the diurnal variation of the convective properties, two (2) important convective properties were selected for discussion; the Precipitation Feature (PF) Flashcount and the system sizes. These properties are important thunderstorm and Mesoscale Convective System (MCS) parameters. The diurnal locations of the Precipitation Feature (PF) Flashcount during MAM season, in Figures 6(a)-(d), clearly indicate that Flashcount $>275$ in one single system was never observed during the morning (6 Z, Figure 6(b)) diurnal, whereas, the evening (18 Z, Figure 6(d)) diurnal had the most frequent cases (at least 8) of Flashcount exceeding 275 in one single system. This is followed by the night $(0 \mathrm{Z}$, Figure 6(a)) with 7 cases of Flashcount exceeding 275 in one (1) single system. As expected, the morning (6 Z, Figure 6(b)) diurnal had the highest percentage occurrence $(97.30 \%)$ of zero (0) Flashcount, and this is closely followed by the night (0 Z, Figure 6(a)) diurnal with $97.05 \%$ occurrence of zero (0) Flashcount. This means that stratiform precipitation [18], or monsoonal precipitation (see [19]), or vortex type precipitation (see [20]) is dominant during morning (6 Z) hours than other periods of the day. This type of precipitation lasts longer and is more voluminous than the convective type of precipitation. The high presence of Flashcount in the evening period is due to the fact that convective systems are often initiated during the day (12 Z) and reach peak values in the evening (18 Z) time ([21] [22]). Most of the Sudano and Sahel zones could not account for significant Flashcount in the MAM season. During the JJAS season, in Figures 7 (a)-(d), there is only one (1) case of observed Flashcount exceeding 275 in only one (1) single system during the morning (6 Z, Figure 7(b)) diurnal. This morning diurnal had the highest percentage occurrence (98.04\%) of Zero (0) 

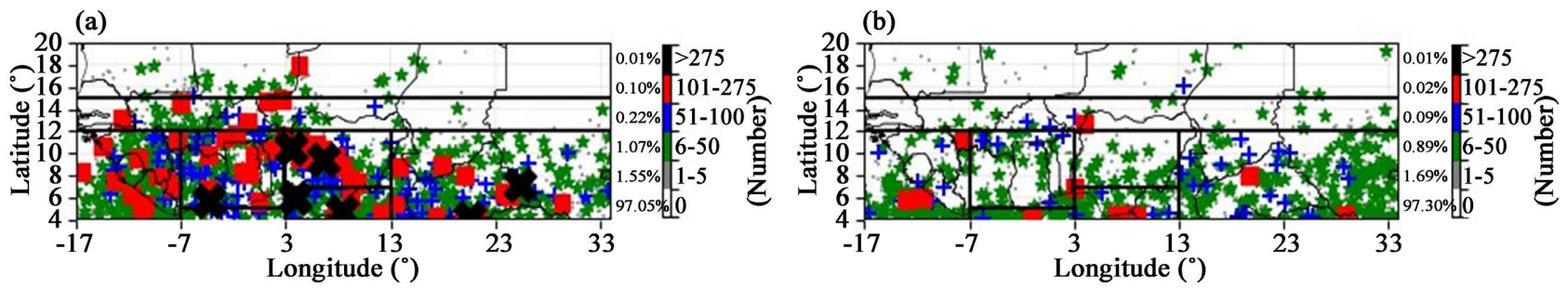

(c)
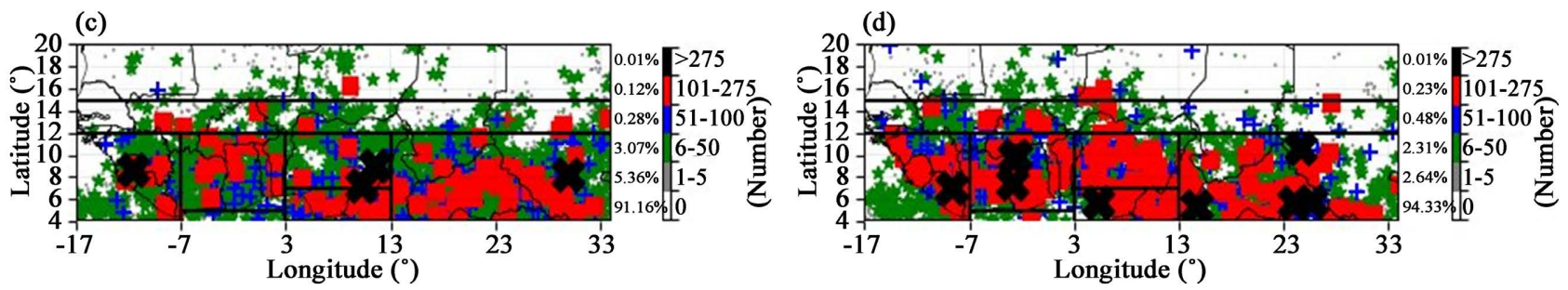

Figure 6. 16 years (1998-2013) diurnal locations of intense PF flashcount during MAM in (a) (00 - 06 Z), (b) (06 - 12 Z), (c) (12 $18 \mathrm{Z}),(\mathrm{d})>18 \mathrm{Z}$. The percentage for each category is indicated. Categories are similar to [27].
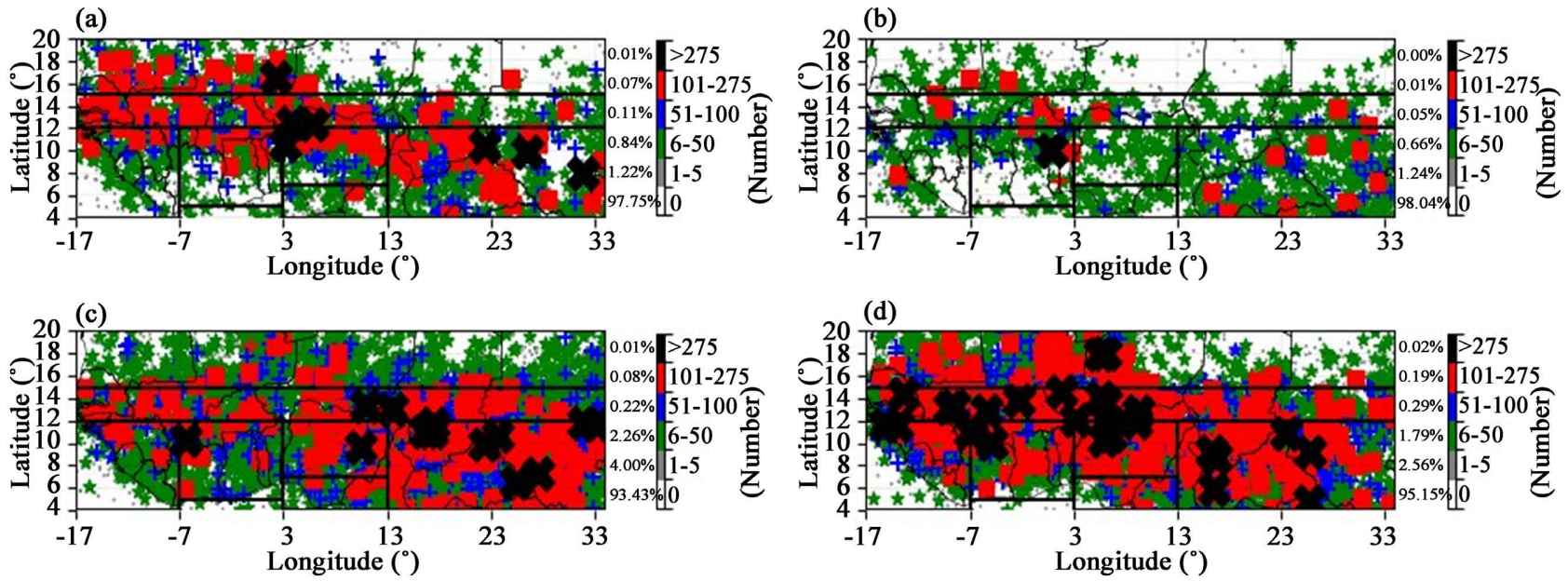

Figure 7. 16 years (1998-2013) diurnal locations of intense PF flashcount during JJAS in (a) (00 - 06 Z), (b) (06 - 12 Z), (c) (12 - 18 $\mathrm{Z})$, (d) $>18 \mathrm{Z}$. The percentage for each category is indicated. Categories are similar to [27].

Flashcount in sixteen (16) years of morning time observation of the TRMM satellite Lightning Imaging Sensor (LIS). The evening (18 Z, Figure 7(d)) diurnal indicated the highest frequency or number of cases of Flashcount exceeding 275 in a single system. This is closely followed by the day (12 Z, Figure $7(\mathrm{c})$ ) diurnal in the JJAS season. As were in previous discussions, the eastern Sudano and Sahel zones lack significant number of Flashcount. [23] had suggested that ENSO effect on rainfall variability is limited to eastern Sahel. They found that the Pacific Ocean is the most important agent in producing the decadal rainfall reduction over the eastern Sahel. The latitudinal extent of the Flashcount reached the northernmost extent of western Sahel zone. Transport of moisture fluxes rarely reached the eastern locations of the Sudano and Sahel zones during MAM (not shown); this is evident in the diurnal Flashcount climatology distribution in these locations, which been extremely few at all periods ((00 Z - 06 Z), (06 Z - 12 Z), (12 Z - $18 \mathrm{Z}),(18 \mathrm{Z}-23 \mathrm{Z})$ ), particularly in the eastern Sahel zone. This may be 
because less than $40 \%$ of the monsoonal moisture reached this zone as suggested by [24]. As was the case in the MAM season, the peak occurrence of Flashcount was observed in the evening (18 Z) period following similar argument that convective systems are often initiated during the day $(12 \mathrm{Z})$ and reached peak values in the evening (18 Z) diurnal ([25] [26]). Generally, Flash count is most frequent during the day $(12 \mathrm{Z})$ and evening $(18 \mathrm{Z})$ periods in both MAM and JJAS season (([25] [26]). This is a clue that convective and thus Mesoscale Convective systems could be more dominant during the day and evening periods whereas stratiform precipitation is dominant during the night and morning periods. This research work hereby concludes that most precipitation occurring in the morning originated from stratiform precipitation, which is often long-lived and voluminous.

The MAM season, in Figures 8(a)-(d), also showed that extremely large system sizes are least frequent during day $(12 \mathrm{Z}$, Figure $8(\mathrm{c})$ ) diurnal as were observed for the MAM climatology. There are only two (2) separate or individual observed system sizes that exceeded $80,000 \mathrm{~km}^{2}$ in the whole of sixteen (16) years TRMM observation of day (12 Z, Figure $8(\mathrm{c})$ ) time diurnal. As expected, the evening (18 Z, Figure 8(d)) and night (0 Z, Figure 8(a)) diurnals had the highest frequencies or number of cases of system sizes that exceeded $80,000 \mathrm{~km}^{2}$. The morning (6 Z, Figure $8(\mathrm{~b})$ ) diurnal indicated the highest percentage frequency or occurrences (95.42\%) of sizes in the range of $0-639 \mathrm{~km}^{2}$, and this is followed by the night ( $0 \mathrm{Z}$, Figure 8 (a)) which had $95.29 \%$ of system sizes in the range of $0-639 \mathrm{~km}^{2}$. In the JJAS season, more extremely large system sizes were observed in each of the diurnals, which is consistent with results from [3] that larger system sizes are more frequent during JJAS than during MAM based on climatology of Precipitation Features investigated in their study. The day (12 Z, Figure 9(c)) and evening (18 Z, Figure 9(d)) diurnals have the least number of cases of system sizes which exceeded $80,000 \mathrm{~km}^{2}$, while the night $(0 \mathrm{Z}$, Figure 9(a)) and morning (6 Z, Figure 9(b)) diurnals indicated the highest percentage occurrence, and hence number of cases, of extremely large system sizes which exceeded $80,000 \mathrm{~km}^{2}$ during the JJAS season. Similar to the MAM season, the
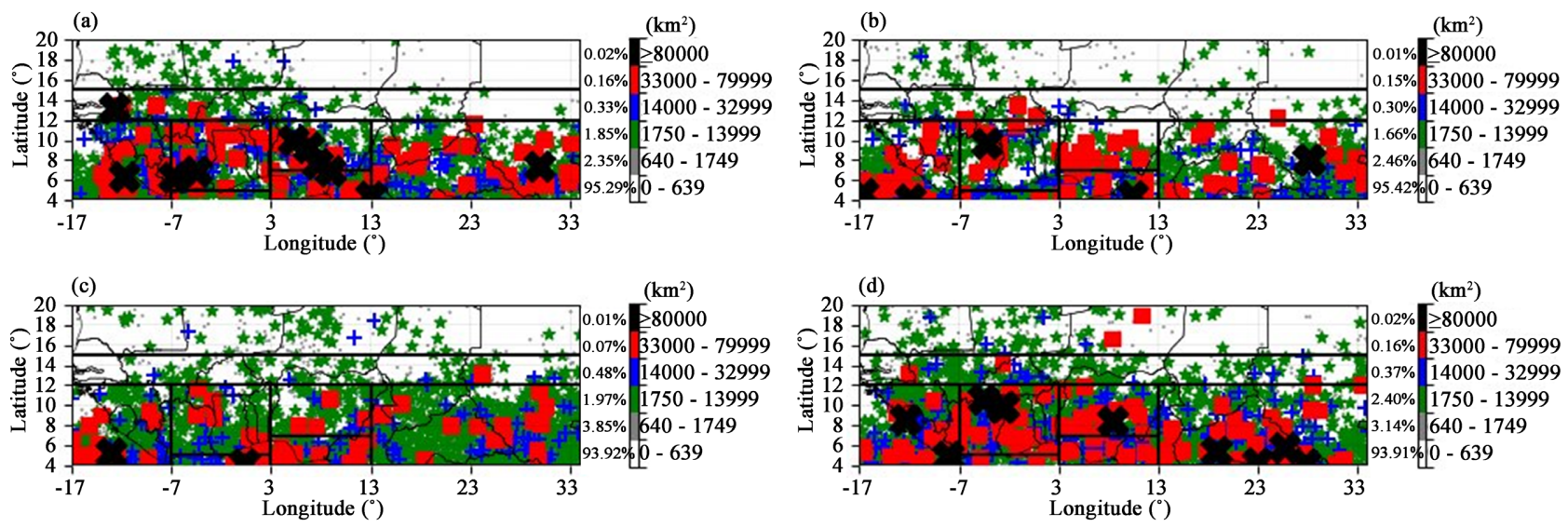

Figure 8. 16 years (1998-2013) diurnal locations of intense PF system sizes during MAM in (a) (00 - 06 Z), (b) (06 - 12 Z), (c) (12 $18 \mathrm{Z})$, (d) $>18 \mathrm{Z}$. The percentage for each category is indicated. Categories are similar to [27]. 

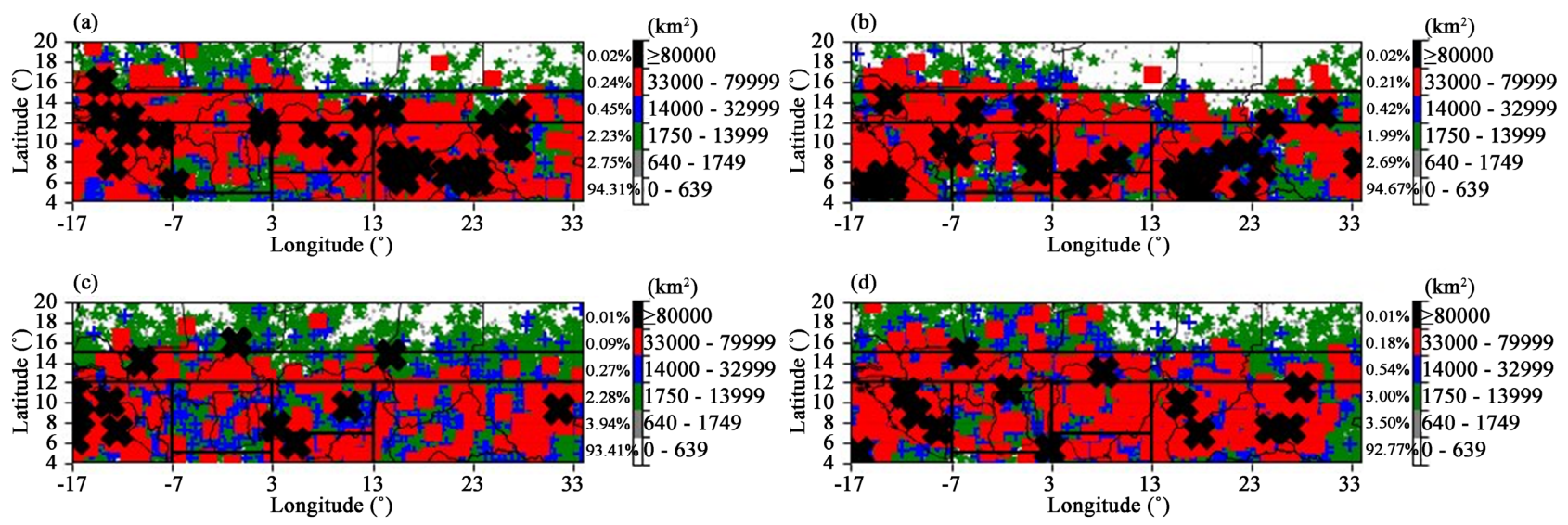

Figure 9. 16 years (1998-2013) diurnal locations of intense PF system sizes during JJAS in (a) (00 - 06 Z), (b) (06 - 12 Z), (c) (12 $18 \mathrm{Z})$, (d) $>18 \mathrm{Z}$. The percentage for each category is indicated. Categories are similar to [27]

morning (6 Z, Figure 9(b)) diurnal indicated the highest percentage frequency or occurrences (94.67\%) of sizes in the range of $0-639 \mathrm{~km}^{2}$, and this is followed by the night ( $0 \mathrm{Z}$, Figure 9 (a)) which had $94.31 \%$ of system sizes in the range of $0-639 \mathrm{~km}^{2}$.

\section{Conclusions}

This research work investigated the diurnal variation of rainfall and two convective properties (flash count and system sizes) at six (6) hour intervals.

Systems with an extremely large number of Flashcount and system sizes were dominant during day-time $(12 \mathrm{Z})$ and evening periods $(18 \mathrm{Z})$ than other diurnals in both MAM and JJAS, whereas systems with extremely few Flashcounts were dominant during morning diurnals, which constituted most of the stratiform precipitation in the morning diurnals. This is a clue that convective and thus Mesoscale Convective systems could be more dominant during the day and evening periods whereas stratiform precipitation is dominant during the night and morning periods.

Thus, the two (2) convective properties considered have shown different diurnal characteristics. While the flash count is less frequent during the morning period and most frequent during the evening period, larger system sizes were observed to be less frequent during the daytime and most frequent during the nighttime. Also, as was observed, the eastern Sudano and Sahel zones seemed to be a dry zone that lacks moisture, and hence rainfall and convective systems. This may be because less than $40 \%$ of the monsoonal moisture reached this zone. It was also observed that convective properties follow the northward migration of the Intertropical Convergence Zone (ITCZ).

Results presented had shown the importance of diurnal variation in understanding precipitation, temperature, flash count, system sizes patterns at diurnal scales, and understanding land-ocean contrast, precipitation and wind field anomaly at diurnal scales. Future work intends to fully investigate the observed dipole between the two Savannahs (CASS and Nigeria Savannah), night and day 
time anomaly in the CASS zone, and the consistent dryness in the Eastern Sudano and Sahel zones, which are key findings in this research work.

\section{Acknowledgements}

Data for this work were downloaded from TRMM Precipitation Feature database of Texas A\&M University Corpus Christi (TAMUCC), USA. This work was supported by the U.K. Research and Innovation as part of the Global Challenges Research Fund, Grant NE/P021077/1 (GCRF African SWIFT).

\section{Conflicts of Interest}

The authors declare no conflicts of interest regarding the publication of this paper.

\section{References}

[1] Yang, G.Y. and Slingo, J. (2001) The Diurnal Cycle in the Tropics. Monthly Weather Review, 129, 784-801. https://doi.org/10.1175/1520-0493(2001)129<0784:TDCITT>2.0.CO;2

[2] Dia-Diop, A., Zebaze, S., Wade, M., Djiondo, R., Diop, B., Efon, E. and Lenouo, A. (2020) Interannual Variability of Rainfall over the West Africa Sahel. Journal of Geoscience and Environment Protection, 8, 85-101. https://doi.org/10.4236/gep.2020.83007

[3] Balogun, R.A., Liu, C., Adeyewa, Z.D., Okogbue, E.C. and Adesanya, E.A. (2019) Intraseasonal and Seasonal Variability of Convective Properties of Monsoon Precipitation Systems over West and Central Africa. Theoretical and Applied Climatolo$g y$, 137, 1715-1728. https://doi.org/10.1007/s00704-018-2692-1

[4] Nesbitt, S.W. and Zipser, E.J. (2003) The Diurnal Cycle of Rainfall and Convective Intensity According to Three Years of TRMM Measurements. Journal of Climate, 16, 1456-1475. https://doi.org/10.1175/1520-0442(2003)016<1456:TDCORA >2.0.CO;2

[5] Mohr, K.I. (2004) Interannual, Monthly, and Regional Variability in the Wet Season Diurnal Cycle of Precipitation in Sub-Saharan Africa. Journal of Climate, 17, 2441-2453. https://doi.org/10.1175/1520-0442(2004)017<2441:IMARVI>2.0.CO;2

[6] Vemado, F. and Pereira Filho, A. (2021) Convective Rainfall in Lake Victoria Watershed and Adjacent Equatorial Africa. Atmospheric and Climate Sciences, 11, 373-397. https://doi.org/10.4236/acs.2021.113022

[7] Rowell, D.P. and Milford, J.R. (1993) On the Generation of African Squall Lines. Journal of Climate, 6, 1181-1193. https://doi.org/10.1175/1520-0442(1993)006<1181:OTGOAS >2.0.CO;2

[8] Hodges, K.I. and Thorncroft, C.D. (1997) Distribution and Statistics of African Mesoscale Convective Weather Systems Based on the ISCCP Meteosat Imagery. Monthly Weather Review, 125, 2821-2837. https://doi.org/10.1175/1520-0493(1997)125<2821:DASOAM>2.0.CO;2

[9] Kummerow, C., Barnes, W., Kozu, T., Shiue, J. and Simpson, J. (1998) The Tropical Rainfall Measuring Mission (TRMM) Sensor Package. Journal of Atmospheric and Oceanic Technology, 15, 809-817. https://doi.org/10.1175/1520-0426(1998)015<0809:TTRMMT>2.0.CO;2

[10] Simmons, A., Uppala, S., Dee, D. and Kobayashi, S. (2007) ERA-Interim: New 
ECMWF Reanalysis Products from 1989 Onwards. ECMWF Newsletter, 110, 25-35.

[11] Dee, D.P., et al. (2011) The ERA-Interim Reanalysis: Configuration and Performance of the Data Assimilation System. Quarterly Journal of the Royal Meteorological Society, 137, 553-597. https://doi.org/10.1002/qj.828

[12] Brandt, Mbow, M.C., Diouf, A.A., Verger, A., Samimi, C. and Fensholt, R. (2014) Ground and Satellite Based Evidence of the Biophysical Mechanisms behind the Greening Sahel. Global Change Biology, 21, 1610-1620. https://doi.org/10.1111/gcb.12807

[13] Maidment, R.I., Allan, R.P. and Black, E. (2015) Recent Observed and Simulated Changes in Precipitation over Africa. Geophysical Research Letters, 42, 8155-8164. https://doi.org/10.1002/2015GL065765

[14] Nicholson, S.E. (2013) The West African Sahel: A Review of Recent Studies on the Rainfall Regime and Its Interannual Variability. ISRN Meteorology, 2013, Article ID: 453521. https://doi.org/10.1155/2013/453521

[15] Churchill, O., Belay, D. and Sium, T. (2014) Characterization of West African Jet Streams and Their Association to ENSO Events and Rainfall in ERA-Interim 1979-2011. Advances in Meteorology, 2014, Article ID: 405617. https://doi.org/10.1155/2014/405617

[16] Swaine, M.D., Hawthorne, W.D. and Orgle, T.K. (1992) The Effects of Fire Exclusion on Savanna Vegetation at Kpong, Ghana. Biotropica, 24, 166-172.

https://doi.org/10.2307/2388670

[17] Fasullo, J. (2011) A Mechanism for Land-Ocean Contrasts in Global Monsoon Trends in a Warming Climate. Climate Dynamics, 39, 1137-1147. https://doi.org/10.1007/s00382-011-1270-3

[18] Janiga, M.A. and Thorncroft, C.D. (2014) Convection over Tropical Africa and the East Atlantic during the West African Monsoon: Regional and Diurnal Variability. Journal of Climate, 27, 4159-4188. https://doi.org/10.1175/JCLI-D-13-00449.1

[19] Omotosho, J.B. (1985) The Separate Contributions of Line Squalls, Thunderstorms, and the Monsoon to the Total Rainfall in Nigeria. Journal of Climatology, 5, 543-552. https://doi.org/10.1002/joc.3370050507

[20] Fink, A.H., Vincent, D.G. and Ermert, V. (2006) Rainfall Types in the West African Sudanian Zone during the Summer Monsoon 2002. Monthly Weather Review, 134, 2143-2164. https://doi.org/10.1175/MWR3182.1

[21] Geerts, B. and Dejene, T. (2005) Regional and Diurnal Variability of the Vertical Structure of Precipitation Systems in Africa Based on Spaceborne Radar Data. Journal of Climate, 18, 893-916. https://doi.org/10.1175/JCLI-3316.1

[22] Huang, X., Hu, C., Huang, X., Chu, Y., Tseng, Y., Zhang, G.J. and Lin, Y. (2018) A Long-Term Tropical Mesoscale Convective Systems Dataset Based on a Novel Objective Automatic Algorithm. Climate Dynamics, 51, 3145-3159. https://doi.org/10.1007/s00382-018-4071-0

[23] Bader, J. and Latif, M. (2003) The Impact of Decadal-Scale Indian Ocean Sea Surface Temperature Anomalies on Sahelian Rainfall and the North Atlantic Oscillation. Geophysical Research Letters, 30, 2169-2173. https://doi.org/10.1029/2003GL018426

[24] Salih, A.A.M., Zhang, Q., Pausata, F.S.R. and Tjernström, M. (2016) Sources of Sahelian-Sudan Moisture: Insights from a moisture-Tracing Atmospheric Model. Journal of Geophysical Research: Atmospheres, 121, 7819-7832. https://doi.org/10.1002/2015JD024575 
[25] Dai, A. (2001) Global Precipitation and Thunderstorm Frequencies. Part II: Diurnal Variations. Journal of Climate, 14, 1112-1128.

https://doi.org/10.1175/1520-0442(2001)014<1112:GPATFP >2.0.CO;2

[26] Dai, A., Lin, X. and Hsu, K.L. (2007) The Frequency, Intensity, and Diurnal Cycle of Precipitation in Surface and Satellite Observations over Low- and Mid-Latitudes. Climate Dynamics, 29, 727-744. https://doi.org/10.1007/s00382-007-0260-y

[27] Zipser, E.J., Liu, C., Cecil, D.J., Nesbitt, S.W. and Yorty, S. (2006) Where Are the Most Intense Thunderstorms on Earth? Bulletin of the American Meteorological Society, 87, 1057-1072. https://doi.org/10.1175/BAMS-87-8-1057 